\title{
Peningkatan Kapasitas Produksi UMKM Pengolah Pentol Ayam melalui Diversifikasi Olahan Bakso Ikan Patin di Masa Pandemi Covid-19
}

\section{Increased Production Capacity of Chicken Meatballs Processing SMEs through Diversification of Processed Catfish Meatballs during the Covid-19 Pandemic}

Iin Khusnul Khotimah*
Yuspihana Fitrial
Yasmin Finivera Putri
Rizqina Ananda Putri
Department of Fisheries Science,
Universitas Lambung Mangkurat,
Banjarbaru, South Kalimantan,
Indonesia
email:
iin.khusnul.khotimah@ulm.ac.id
Kata Kunci
Bakso ikan patin
Covid-19
Pentol ayam
Keywords:
Catfish meatballs
Covid-19
Chicken meatballs
Published: June 2021

\begin{abstract}
Abstrak
Usaha Mikro, Kecil, dan Menengah (UMKM) pentol ayam gurih "Cici” adalah salah satu usaha masyarakat berbasis pangan lokal yang ada di Desa Sekumpul Kecamatan Martapura Kabupaten Banjar Kalimantan Selatan. Di masa menghadapi wabah Covid-19 ini usaha mereka tidak beroperasi lagi sekitar empat bulan terakhir, karena harga bahan baku ayam yang sangat mahal. Oleh sebab itu perlu diberikan inovasi teknologi yang lain agar mereka tetap bisa mengembangkan usaha tersebut. Potensi ikan patin sebagai bahan baku pengganti ayam di desa ini tersedia, karena harganya yang lebih murah dan mudah diperoleh di pasar Martapura. Tujuan dari kegiatan ini adalah memanfaatkan ikan patin dalam pengolahan bakso. Metode yang digunakan penyuluhan, demonstrasi, partisipatif dan pendampingan. Hasil yang diperoleh dari pelaksanaan pengabdian adalah mitra dapat memanfaatkan ikan patin sebagai upaya penggunaan bahan baku yang lebih murah dan mudah memperolehnya dalam pengolahan bakso, peningkatan kapasitas produksi pentol ayam melalui pengolahan bakso ikan patin, dan pengolahan bakso ikan patin sebagai solusi diversifikasi produk olahan bakso dengan isi sayur-sayuran sehat dalam menghadapi masa pandemi Covid-19.
\end{abstract}

\begin{abstract}
Micro, Small, and Medium Enterprises (MSMEs) "Cici" savory chicken sticks are local food-based community businesses in Sekumpul Village, Martapura District, Banjar Regency, South Kalimantan. When facing the Covid-19 outbreak, their business has stopped operating for the last four months because the price of raw chicken is very high. Therefore, it is necessary to provide other technological innovations so that they can continue to develop these businesses. The potential of catfish as a raw material for chicken substitutes in this village is available because the price is lower and easy to obtain at the Martapura market. The purpose of this activity is to utilize catfish in meatball processing. The methods used are counseling, demonstration, participatory and mentoring. The results obtained from the implementation of service are partners can utilize catfish as an effort to use cheaper and easier raw materials in meatball processing, increase chicken meatballs production capacity through processing catfish meatballs, and processing catfish meatballs as a diversification solution for processed meatball products with fill healthy vegetables in the face of the Covid-19 pandemic.
\end{abstract}

(C) 2021 Iin Khusnul Khotimah, Yuspihana Fitrial, Yasmin Finivera Putri, Rizqina Ananda Putri. Published by Institute for Research and Community Services Universitas Muhammadiyah Palangkaraya. This is Open Access article under the CC-BY-SA License (http://creativecommons.org/licenses/by-sa/4.0/). DOI: https://doi.org/10.33084/pengabdianmu.v6i4.1868

\section{PENDAHULUAN}

Usaha Mikro, Kecil, dan Menengah (UMKM) pentol ayam gurih "Cici" adalah salah satu usaha masyarakat berbasis pangan lokal yang ada di Desa Sekumpul Kecamatan Martapura Kabupaten Banjar Kalimantan Selatan. Calon pengusaha yang dipilih adalah ibu Juriah 
Natipah sebagai pemilik usaha. Usaha ekonomis yang dilakukan adalah mengolah dan menjual pentol ayam gurih.

Usaha pembuatan pentol ayam gurih sudah mereka lakoni selama hampir 22 bulan, setiap bulan mampu produksi selama 4 kali dengan kapasitas sekali produksi $6 \mathrm{~kg}$ daging ayam (modal Rp 500.000,00) menghasilkan \pm 900 biji pentol ayam gurih. Pentol ayam gurih yang dihasilkan dijual dalam bentuk paket @ 50 biji dengan harga Rp 35.000,00. Dalam satu kali produksi mampu menjual 18 paket @ Rp 35.000,00 = Rp 630.000,00, sehingga keuntungan yang diperoleh setiap sekali produksi sekitar Rp 130.000,00, tetapi dimasa menghadapi wabah Covid- 19 ini usaha mereka tidak beroperasi lagi sekitar 4 bulan terakhir ini karena harga bahan baku ayam yang sangat mahal. Oleh sebab itu perlu diberikan inovasi teknologi yang lain agar mereka tetap bisa mengembangkan usaha tersebut (Ratnasari et al., 2018; Damanik et al., 2017). Potensi ikan patin sebagai bahan baku pengganti ayam di desa ini tersedia karena harganya yang lebih murah (Naibaho et al., 2015) dan mudah diperoleh di pasar Martapura.

Permasalahan yang dihadapi oleh UMKM Pentol Ayam Gurih "Cici” adalah sebagai berikut:

1. Harga bahan baku ayam yang mahal saat ini sehingga perlu mengganti bahan baku yang lebih murah dan mudah memperolehnya yaitu menggunakan ikan patin.

2. Kapasitas produksi yang masih rendah

3. Diperlukan inovasi produk dengan diversifikasi pengolahan bakso ikan patin dengan isi sayursayuran sehat dalam menghadapi masa pandemi Covid-19.

4. Usaha pengolahan pentol ayam gurih sudah dilakukan sejak tahun 2018, tetapi permasalahan yang dihadapi adalah mereka tidak bisa produksi secara rutin karena pasar yang terbatas. Selama ini produksi tersebut hanya berdasarkan pesanan individual.

5. Selain itu, saat ini sudah ada kompetitor produk sejenis yang ada dipasaran setempat dengan harga yang lebih murah. Oleh karena itu diperlukan upaya untuk peningkatan kapasitas pengolahan pentol ayam dengan melakukan diversifikasi produk bakso ikan patin agar dapat bersaing dengan produk dipasaran.

6. Selain itu manajemen usaha masih dikelola secara tradisional dan kekeluargaan. Manajemen usaha dan keuangan diatur secara sederhana tanpa perhitungan laba rugi yang sesuai (Kusumawardhany, 2020). Kegiatan Ipteks berbasis masyarakat ini diharapkan dapat meningkatkan pengetahuan dan keterampilan calon pengusaha untuk melihat peluang pasar dan peningkatan produktivitas.

Calon pengusaha yang dipilih untuk kegiatan IPTEKS berbasis Masyarakat ini adalah:

1. Nama UMKM :Pentol ayam gurih "Cici"

2. Pemilik :Ibu Juriah Natipah

3. Alamat :Jl.Sekumpul Raya Komplek Bukit Sekumpul Blok B No.10 Desa Sekumpul Kecamatan Martapura Kabupaten Banjar Kalimantan Selatan

4. Usaha : Pengolahan pentol daging ayam gurih

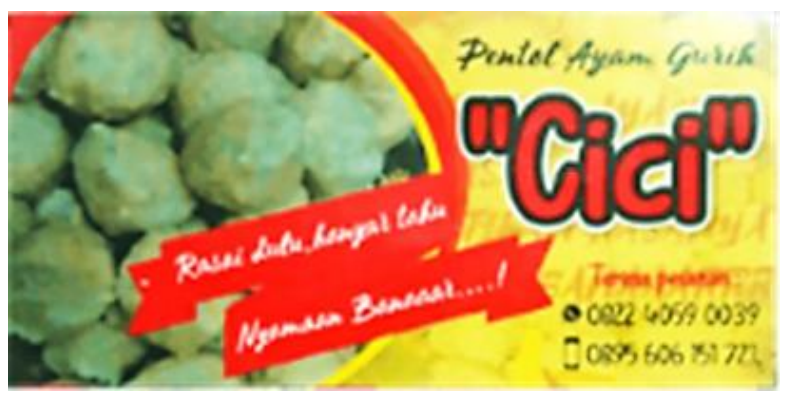

Gambar 1. Label produk pentol ayam gurih “Cici” 


\section{METODOLOGI}

Kegiatan pengabdian kepada masyarakat ini dilaksanakan dengan 3 metode yaitu penyuluhan tentang pengolahan bakso ikan patin, demostrasi pengolahan bakso ikan patin isi sayur-sayuran, dan pendekatan serta pendampingan usaha. Pendekatan yang dilakukan adalah model partisipatif dan pendampingan diharapkan terjadi dalam bentuk pengembangan usaha melalui peningkatan produksi pengolahan bakso ikan patin dan diversifikasi olahan bakso ikan patin berisi sayur-sayuran sehat.

\section{HASIL DAN PEMBAHASAN}

Pelaksanaan kegiatan pengabdian kepada masyarakat diawali dengan kegiatan persiapan meliputi survei lokasi, pembelian peralatan dan bahan yang digunakan dalam pengolahan bakso ikan patin isi sayur-sayuran. Selanjutnya Tim Pengabdian menentukan waktu untuk pembuat produk bakso ikan patin isi sayur-sayuran. Pengolahan bakso ikan patin isi sayur-sayuran dilaksanakan di Laboratorium Pengolahan Hasil Perikanan Fakultas Perikanan dan Kelautan Universitas Lambung Mangkurat Banjarbaru. Seluruh kegiatan pengolahan bakso ikan patin isi sayur-sayuran didokumentasikan dan dibuat video, visual cara pengolahan bakso ikan patin isi sayur-sayuran. Dokumentasi pengolahan bakso ikan patin isi sayursayuran dapat dilihat pada gambar berikut:

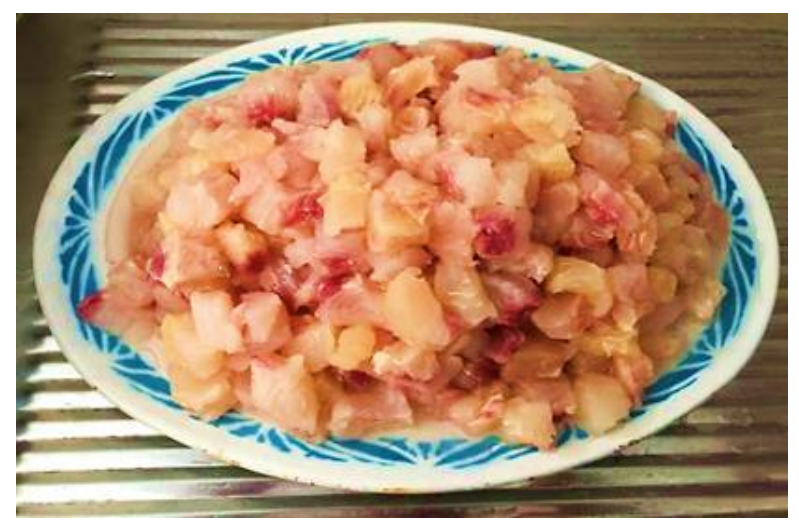

Gambar 2. Daging ikan patin di potong dadu

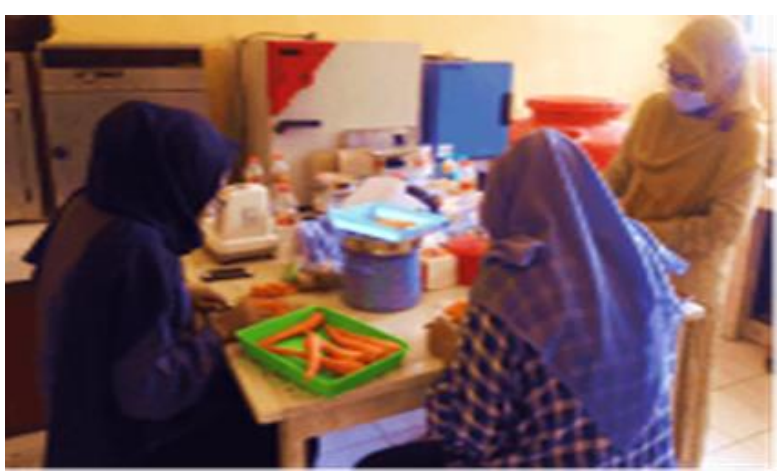

Gambar 3. Persiapan sayuran untuk isi

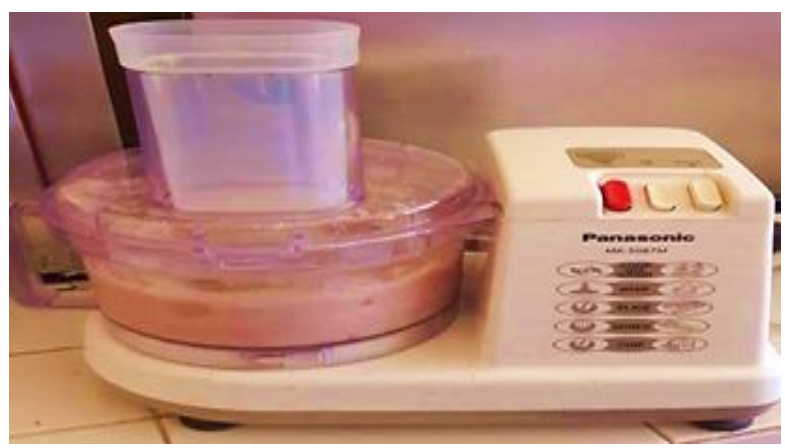

Gambar 4. Pencampuran bahan

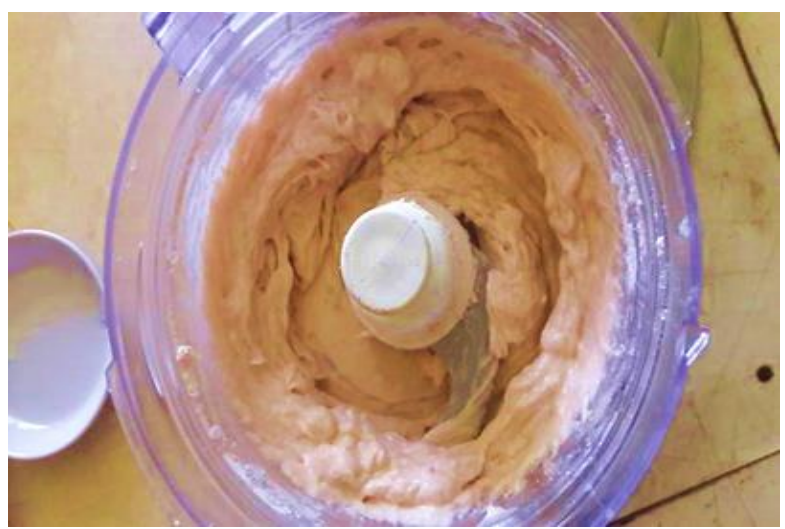

Gambar 5. Adonan siap di cetak

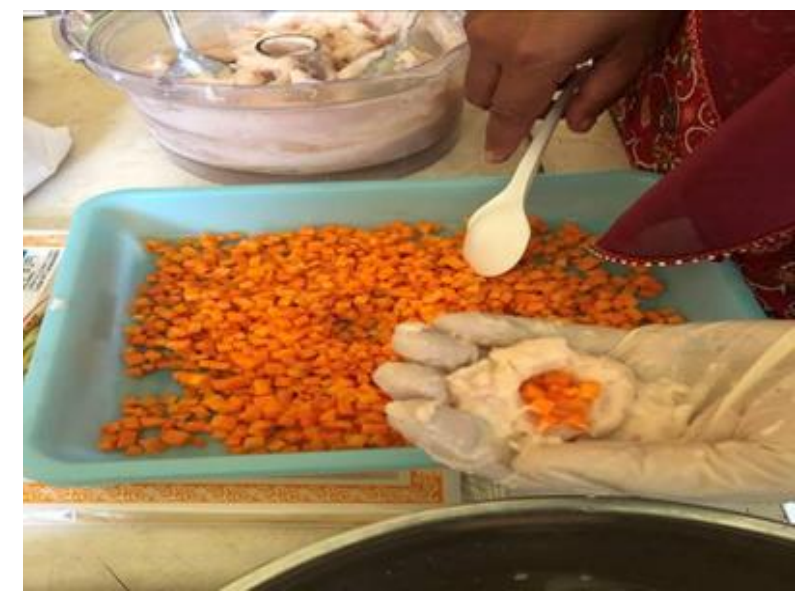

Gambar 6. Adonan diisi sayur 


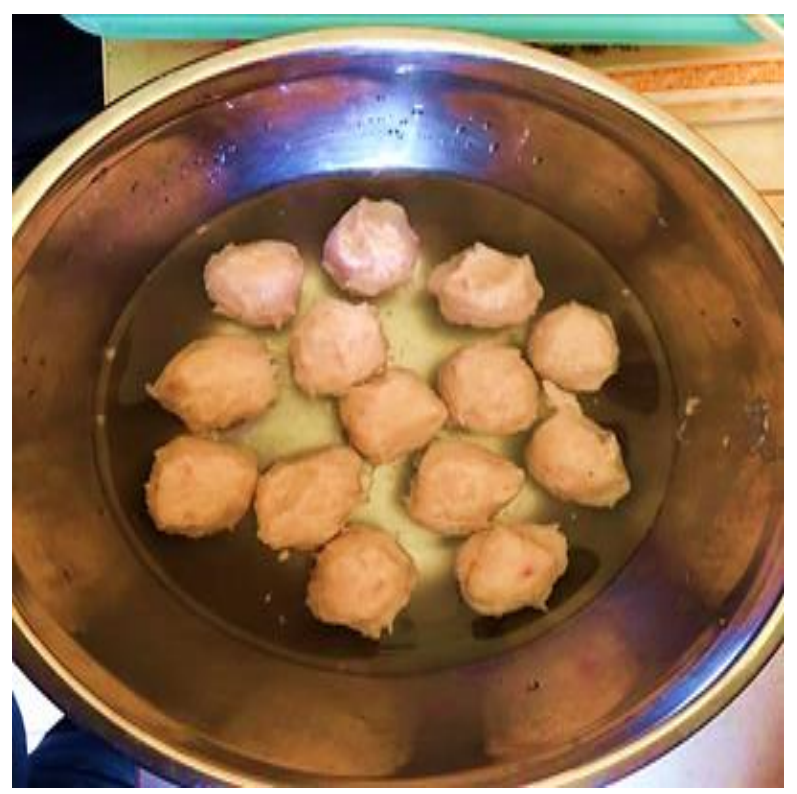

Gambar 7. Bakso direndam dalam air es dan direbus hingga mengapung

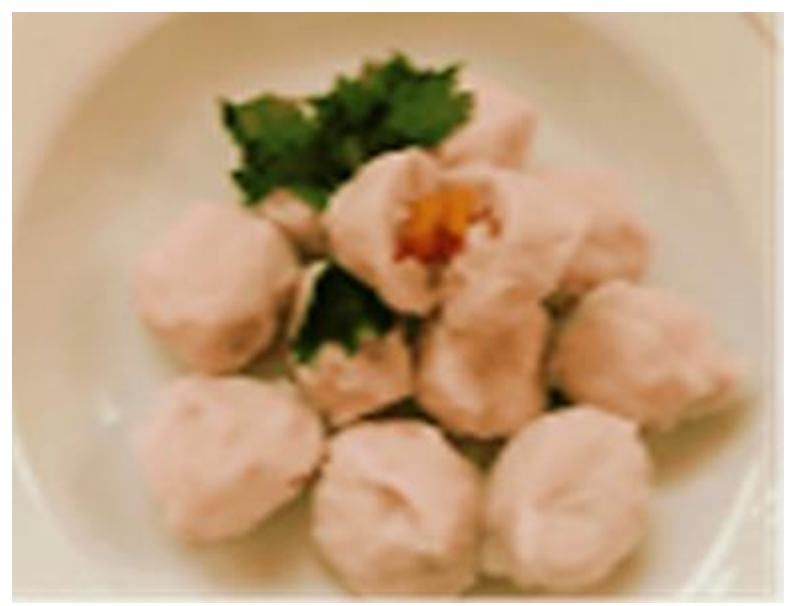

Gambar 8. Bakso ikan patin isi sayuran siap dikonsumsi

Kegiatan pengolahan bakso ikan patin isi sayuran dan video cara pengolahannya telah selesai dikerjakan oleh tim pengabdian, selanjutnya kegiatan penyuluhan terhadap mitra dilakukan dengan cara mengirimkan video cara pengolahan bakso ikan patin isi sayuran tersebut ke mitra via chat WhatsApp (WA) seperti terlihat pada Gambar 9. Penyuluhan merupakan suatu usaha menyebarluaskan hal-hal yang baru agar masyarakat tertarik, berminat dan bersedia untuk melaksanakannya dalam kehidupan mereka sehari-hari (Siswanto, 2012).

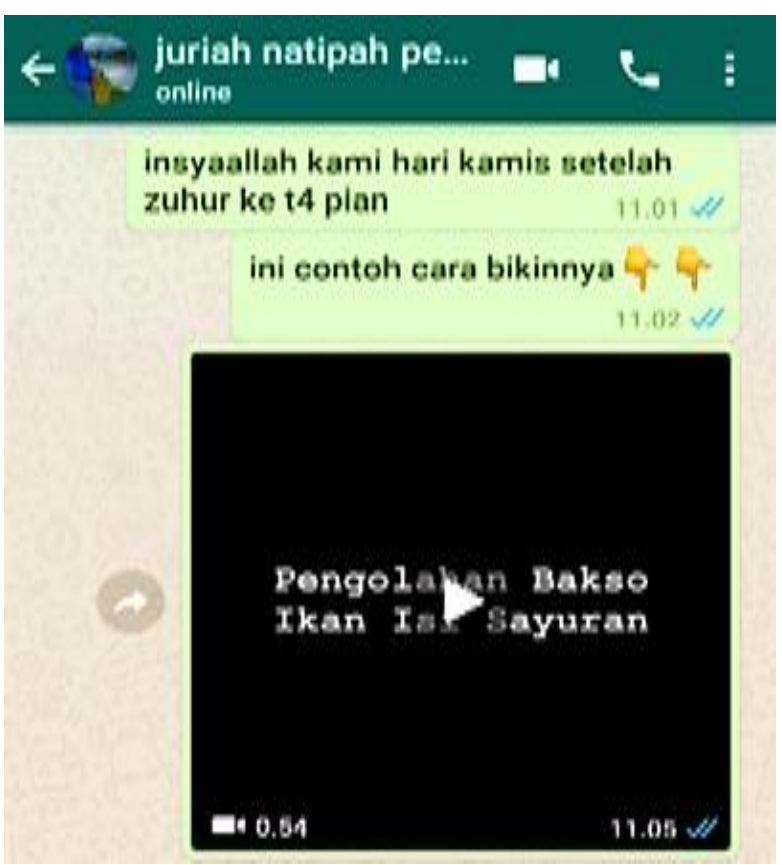

Gambar 9. Video pengolahan bakso ikan patin isi sayuran dikirim ke mitra via chat WA

Definisi penyuluhan lebih lanjut menurut Subejo (2010) adalah proses perubahan perilaku di kalangan masyarakat agar mereka tahu, mau dan mampu melakukan perubahan demi tercapainya peningkatan produksi, pendapatan atau keuntungan dan perbaikan kesejahteraannya. Menurut Suhardjo (2003), penyuluhan adalah suatu upaya perubahan perilaku manusia yang dilakukan melalui pendekatan edukatif, yaitu rangkaian kegiatan yang dilakukan secara sistematik, terencana dan terarah dengan peran serta aktif individu maupun kelompok atau masyarakat, untuk memecahkan masalah masyarakat dengan memperhitungkan ekonomi - budaya setempat. Menurut Setiana (2005), penyuluhan merupakan proses perubahan perilaku yang berkelanjutan, dimana perubahan yang dituntut tidak semata-mata karena penambahan pengetahuan saja, namun diharapkan juga adanya perubahan pada keterampilan sekaligus sikap mantap yang menjurus kepada tindakan atau kerja yang lebih baik, produktif, dan menguntungkan.

Media dan alat bantu yang digunakan dalam kegiatan penyuluhan dapat dalam bentuk leaflet, flipchart (lembar 
balik), film dan video, slide, transparan OHP, papan tulis. Pada masa pandemi Covid-19 ini media dan alat bantu yang digunakan dalam kegiatan penyuluhan menggunakan video. Menurut Setiana (2005), keunggulan media ini antara lain dapat memberikan realita yang memungkinkan sulit direkam kembali oleh mata dan pikiran sasaran, dapat memicu diskusi mengenai sikap dan perilaku, dan dapat merefleksikan kepada diri mereka tentang keadaan yang benar-benar terjadi.

Kegiatan demonstrasi pengolahan bakso ikan patin isi sayur-sayuran bagi mitra dapat dilihat pada Gambar berikut. Menurut Sanjaya (2006), metode demonstrasi merupakan metode dalam pembelajaran dengan menunjukkan proses, situasi, maupun benda tertentu baik asli maupun tiruan. Metode demonstrasi menampilkan proses suatu benda maupun peristiwa yang dicontohkan pengajar sehingga peserta didik dapat memahami dengan lebih mudah (Fartati, 2015). Metode ini dipakai untuk mempertunjukkan sebuah proses atau bagaimana suatu benda bekerja yang berkaitan dengan bahan pembelajaran. Metode demonstrasi adalah metode mengajar dengan memperagakan kejadian, aturan, atau urutan proses, dengan menggunakan media yang relevan dengan materi yang dibahas (Safrinur et al., 2014).

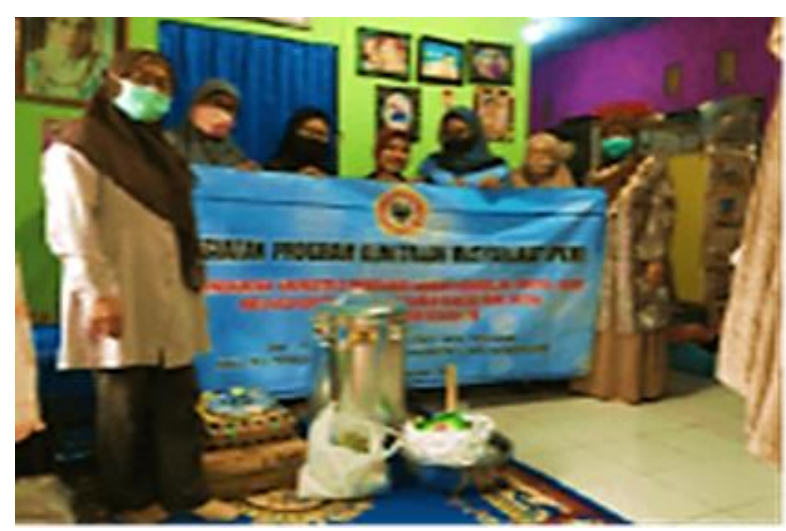

Gambar 10. Foto bersama tim pengabdian dan mitra

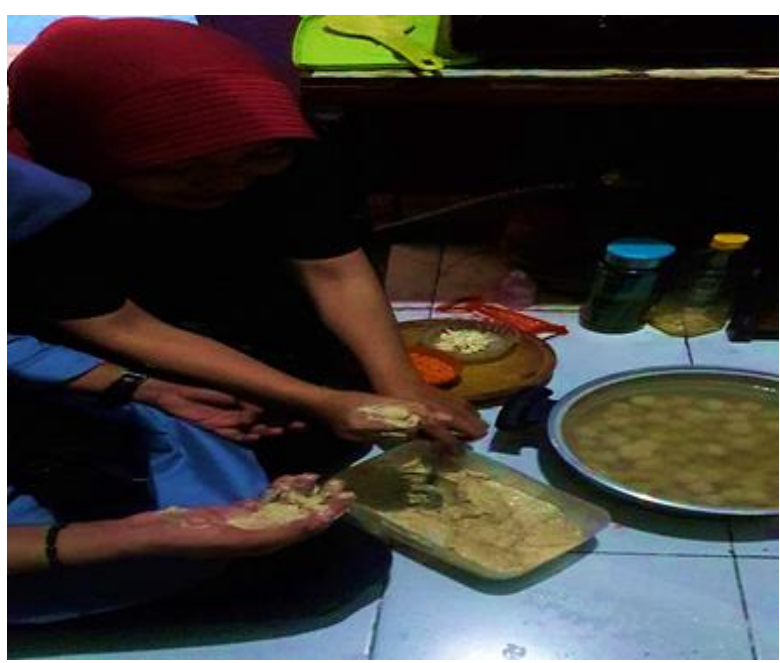

Gambar 11. Demonstrasi pencetakan adonan bakso ikan patin isi sayuran

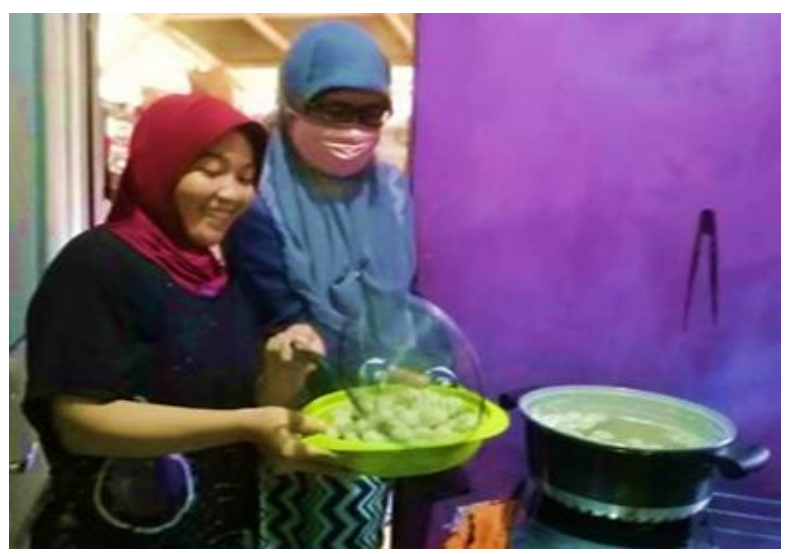

Gambar 12. Bakso ikan patin yang telah dimasak

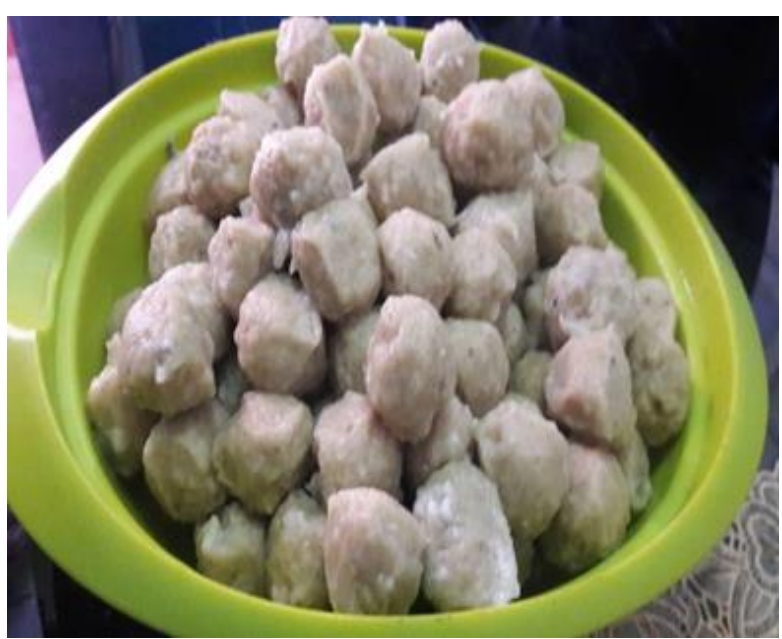

Gambar 13. Bakso ikan patin siap dikonsumsi

Mitra telah berhasil mendemonstrasikan bakso ikan patin isi sayur-sayuran sesuai prosedur yang telah dilihat dari video yang dikirim via chat WA. Adapun resep 
pengolahan bakso ikan patin isi sayur-sayuran adalah sebagai berikut: $500 \mathrm{~g}$ daging ikan patin, $10 \mathrm{~g}$ gula pasir, garam $15 \mathrm{~g}$, 1 sendok teh merica, 1 sendok makan bawang putih goreng, $30 \mathrm{~g}$ tepung sagu, 2 butir putih telur, $200 \mathrm{~g}$ wortel, dan daun bawang. Prosedur cara membuatnya adalah sebagai berikut:

1. Bekukan ikan yang sudah di potong-potong dalam freezer sampai beku

2. Masukkan daging ikan patin yang telah dibekukan dalam food processor dan tambahkan garam dan gula, campurkan hingga homogen

3. Tambahkan merica, bawang puth goreng, dan tepung sagu aduk hingga tercampur rata

4. Masak air sampai mendidih mendidih, matikan kompornya

5. Cetak adonan bulat-bulat dan sebagian adonan diisi dengan sayuran (wortel dan daun bawang yang telah dipotong-potong) masukkan ke air panas tadi dilakukan sampai adonan bakso habis

6. Hidupkan kompor kembali, rebus bakso sampai ngapung ke permukaan air, angkat tiriskan

7. Siap digunakan setelah bakso ikan dingin

Pemasaran produk pentol ayam yang diproduksi mitra selama ini melalui WA dan orang-orang terdekat yang sudah mengenal mitra disekitar Martapura dan Banjarbaru. Sehingga untuk uji coba pemasaran bakso ikan patin isi sayuran masih mengikuti pola pemasaran pentol ayam yang sudah dikenal oleh pelanggan. Pemasaran adalah suatu proses pembelajaran dan manajerial yang membuat individu dan kelompok memperoleh apa yang mereka butuhkan serta inginkan lewat penciptaan dan pertukaran timbal balik produk dan nilai dengan orang lain (Priangani, 2013).

Salah satu upaya tim pengabdian untuk peningkatan kapasitas produksi UMKM pentol ayam ini dalam pemasaran produk bakso ikan patin, yaitu dengan mengundang mitra untuk mengikuti pelatihan gratis untuk strategi pemasaran yang diadakan UPT Laboratorium terpadu ULM pada tanggal 5 Oktober 2020 dengan judul kegiatan “Peran Teknologi Informasi dalam Pemasaran Produk UMKM di Era Revolusi Industri 4.0". Kegiatan tersebut dilaksanakan via online melalui join zoom meeting, meeting ID 98518748283 dan Passcode 536174.

Hasil dari kegiatan pelatihan strategi pemasaran yang dapat diperoleh oleh setiap peserta adalah mendapatkan sertifikat keikutsertaan dalam kegiatan tersebut serta setiap peserta memperoleh modul workshop dari 2 orang narasumber yaitu dari Martha Krisna dan Muliadi, S.Kom., M.Cs. Pengalaman dan transfer ilmu pengetahuan tentang strategi pemasaran melalui media online yang telah digeluti oleh kedua narasumber sangat memotivasi setiap peserta pelatihan untuk memperluas jangkauan pemasaran produk dengan cara membuat Google bisnisku dan accounts Shopee.

Hasil produk bakso ikan patin yang siap untuk dipasarkan dikemas dalam plastik mika yang telah diberi label seperti pada Gambar berikut.

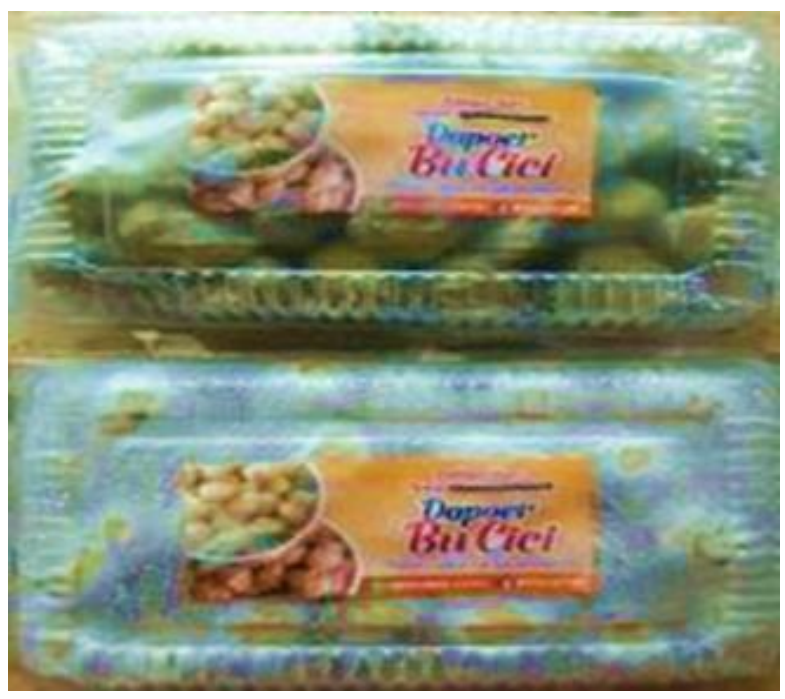

Gambar 14. Bakso ikan patin isi sayuran siap dipasarkan

Kegiatan monitoring tim pengabdian ke mitra sebanyak 3 kali, adapun dokumentasi kegiatan monitoring dan evaluasi dapat dilihat pada gambar berikut ini: 


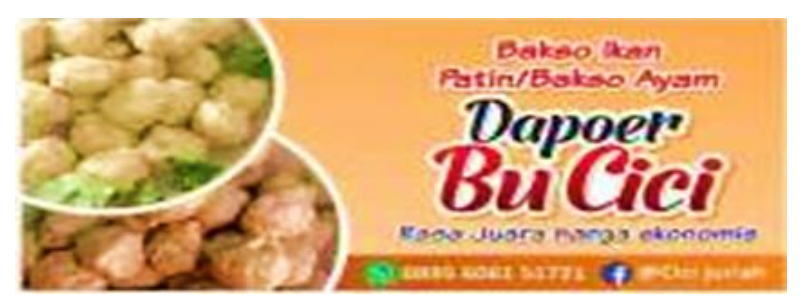

Gambar 15. Label bakso ikan

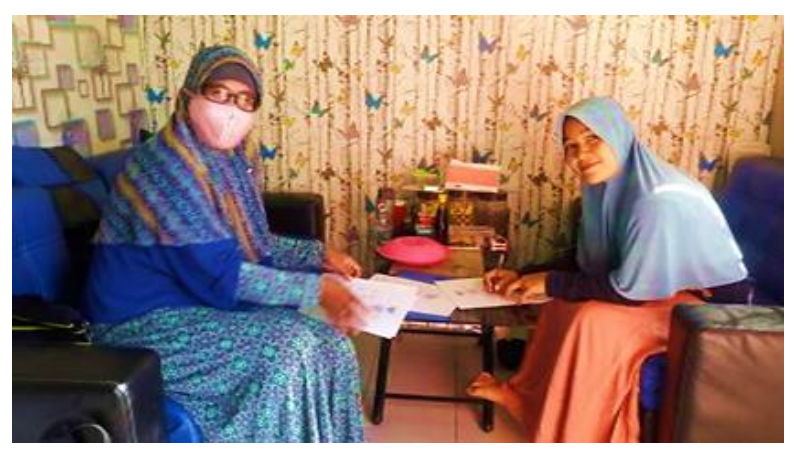

Gambar 15. Diskusi ketua tim dengan mitra

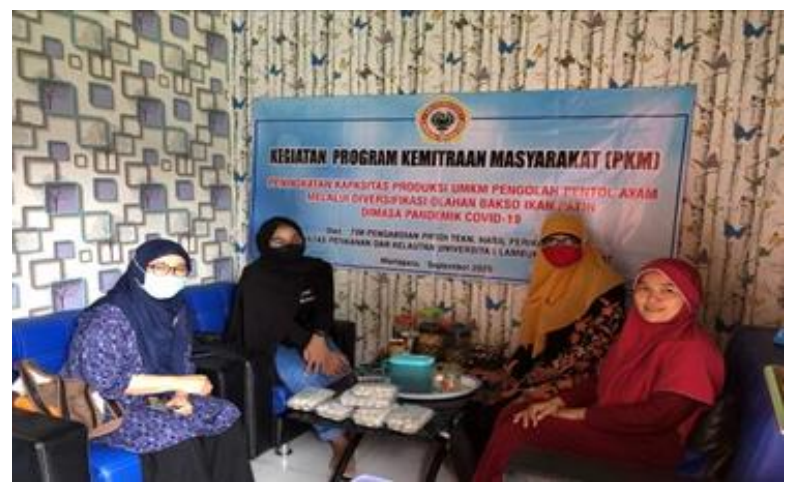

Gambar 16. Tim pengabdi foto bersama mitra

Hasil monitoring dan evaluasi yang dilaksanakan pada tanggal 28 September dan 7 Oktober 2020 menunjukkan bahwa mitra sudah membuat label untuk produk bakso ikan patin dan memproduksi bakso ikan patin pada tanggal 21 September 2020. Pemasaran produk bakso ikan patin mengikuti pola pemasaran dari pentol ayam. Hasil monitoring dan evaluasi pada tanggal 22 Oktober 2020 menunjukkan bahwa penjualan bakso ikan patin isi sayuran yang di produksi pada tanggal 21 September 2010 mitra menggunakan modal sebanyak Rp 500.000,00 menghasilkan sekitar 1.222 biji bakso, dan dijual @ Rp 600,- per bijinya sehingga keuntungan yang dapat diperoleh dari produksi pengolahan bakso ikan patin isi sayur-sayuran ini sekitar Rp 233.200,00.

\section{KESIMPULAN}

Kesimpulan dari kegiatan pengabdian kepada masyarakat ini adalah pengabdian dilaksanakan sebagai upaya penggunaan bahan baku yang lebih murah dan mudah memperolehnya yaitu menggunakan ikan patin dalam pengolahan bakso. Peningkatan kapasitas produksi pentol ayam melalui pengolahan bakso ikan patin. Pengolahan bakso ikan patin sebagai solusi diversifikasi produk olahan bakso dengan isi sayursayuran sehat dalam menghadapi masa pandemik covid-19.

\section{UCAPAN TERIMA KASIH}

Terimakasih disampaikan kepada Universitas Lambung Mangkurat yang telah membiayai sesuai dengan Daftar Isian Pelaksanaan Anggaran (DIPA) SP DIPA023.17.2.677518/2020 Revisi ke 01 tanggal 16 Maret 2020.

\section{REFERENSI}

Damanik, M.R.S., Sriadhi, S., Habibi, M.R., Harefa, M.S. 2017. Diversifikasi Pengolahan Ikan Sebagai Upaya Peningkatan Ekonomi Masyarakat Nelayan Desa Bagan Serdang Kecamatan Pantai Labu Kabupaten Deli Serdang. Jurnal Pengabdian Kepada Masyarakat. 23(4):455-459. https://doi.org/10.24114/jpkm.v23i4.8607

Fartati, F. 2015. Penerapan Metode Demonstrasi Untuk Meningkatkan Hasil Belajar Siswa Pada Materi Penyebab Benda Bergerak Di Kelas II SD No. 1 Polanto Jaya. Jurnal Kreatif Online. 3(4):108-120.

Kusumawardhany, S.I. 2020. Penerapan Akuntansi pada Usaha Mikro, Kecil, dan Menengah (UMKM) (Studi pada UMKM Raja Eskrim) di Kota Kediri. Jurnal Akuntansi dan Perpajakan. 6(2):7681. https://doi.org/10.26905/ap.v6i2.4570

Naibaho, J., Sari, N.I., Suparmi. 2015. Characteristic of Catfish (Pangasius hypophthalmus) Ball with the Addition of Banana's Heart (Musa paradisiaca) on Consumer Acceptance. Jurnal online mahasiswa Fakultas Perikanan dan Ilmu Kelautan Universitas Riau. 2(2):1-8. 
Priangani, A. 2013. Memperkuat Manajemen Pemasaran Dalam Konteks Persaingan Global. Jurnal Kebangsaan: Kajian Manajemen dan Keuangan. 2(4):1-9.

Ratnasari, I., Maryani, M., Al Hidayat, S., Handayani, T. W., Nursiah, N. 2018. Pendampingan Dan Diversifikasi Olahan Ikan Lokal Menjadi Produk Kaki Naga Untuk Pengembangan Kelompok Usaha Masyarakat Di Desa Tiwingan Lama Kecamatan Aranio. PengabdianMu: Jurnal Ilmiah Pengabdian Kepada Masyarakat. https://doi.org/10.33084/pengabdianmu.v3i 2.401

Safrinur, Margiati, K.Y., Halidjah, S. 2014. Penggunaan Metode Demonstrasi Untuk Meningkatkan Aktivitas Dan Hasil Belajar Dalam Pembelajaran IPA Di Sekolah Dasar. Jurnal Pendidikan dan Pembelajaran Khatulistiwa (JPPK). 3(7):1-9.

Sanjaya, W. 2006. Strategi Pembelajaran Berbasis Standar Proses Pendidikan. Jakarta: Kencana Prenada Media Grup

Siswanto, D. 2012. Hakikat Penyuluhan Pembangunan Dalam Masyarakat. Jurnal Filsafat. 22(1):51-68. https://doi.org/10.22146/jf.12985

Setiana, L. 2005. Teknik Penyuluhan dan Pemberdayaan Masyarakat. Bogor: Ghalia Indonesia

Subejo. 2010. Penyuluhan Pertanian. Jakarta: Extension.

Suhardjo. 2003. Berbagai Cara Pendidikan Gizi. Jakarta: Bumi Aksara 